\title{
HUBUNGAN USIA DAN JENIS KELAMIN BERESIKO DENGAN KEJADIAN HIPERTENSI DI KLINIK X KOTA TANGERANG
}

\author{
Eni Nuraeni ${ }^{1}$ \\ ${ }^{1}$ Universitas Muhammadiyah Tangerang, eninoer92@gmail.com
}

\section{INFORMASI ARTIKEL:}

\author{
Riwayat Artikel: \\ Kata kunci: \\ Hipertensi \\ umur \\ riwayat keturunan \\ pendapatan
}

Tanggal di Publikasi: Juli 2019

\begin{abstract}
A B S T R A K
Seseorang dikatakan hipertensi bila memiliki tekanan darah sistolik $\geq 140$ $\mathrm{mmHg}$ dan atau tekanan darah diastolik $\geq 90 \mathrm{mmHg}$, pada pemeriksaan yang berulang. Prevalensi hipertensi di klinik X di Kota Tangerang adalah sebesar $20 \%$.Tujuan penelitian ini untuk mengkaji hubungan umur, jenis kelamin , riwayat keturunan, olahraga, obesitas, status pendidikan, status pekerjaan, status perkawinan dan pendapatan dengan hipertensi di Klinik X di Kota Tangerang pada tahun 2016. Jenis penelitian adalah survei analitik dengan menggunakan rancangan cross sectional. Populasi dalam penelitian ini adalah pengunjung klinik berumur 18 tahun ke atas yang berobat jalan di Klinik X di Kota Tangerang pada tahun 2016, dengan besar sampel sebanyak 210. Pengumpulan data dilakukan dengan data primer melalui wawancara dengan menggunakan kuesioner dan pengukuran tekanan darah, berat badan dan tinggi badan. Analisis data dengan univariat, bivariat, multivariat. Hasil analisis multivariat, didapatkan faktor yang berhubungan dengan hipertensi adalah umur $(\mathrm{p}=0,000 ; \mathrm{OR}=8.431)$, pendapatan $(\mathrm{p}=0.001 ; \mathrm{OR}=4.471)$ dan riwayat keturunan $(0,031 ; \mathrm{OR}=3.744)$ sedangkan variabel olahraga, pekerjaan dan pendidikan merupakan variabel confounding. Umur merupakan faktor dominan yang berhubungan dengan hipertensi. Disarankan kepada Depkes, Dinkes, Puskesmas untuk meningkatkan upaya program promotif, preventif penyakit hipertensi, begitupun Klinik X, yang lebih dikhususkan lagi kepada pasien-pasien rawat jalan terutama yang mempunyai faktor resiko hipertensi.
\end{abstract}




\section{PENDAHULUAN}

Terjadinya transisi epidemiologi yang paralel dengan transisi demografi dan transisi teknologi di Indonesia dewasa ini telah mengakibatkan perubahan pola penyakit dari penyakit infeksi kepenyakit tidak menular (PTM) meliputi penyakit degenerative dan man made diseases yang merupakan factor utama masalah morbiditas dan mortalitas.Terjadinya transisi epidemiologi ini disebabkan terjadinya perubahan sosial ekonomi, lingkungan dan perubahan struktur penduduk, saat masyarakat telah mengadopsi gaya hidup tidak sehat, misalnya merokok, kurang aktivitas fisik, makanan tinggilemakdankalori, serta konsumsi alcohol yang diduga merupakan factor risiko PTM. Pada abad ke-21 ini diperkirakan terjadi peningkatan insidens dan prevalensi PTM secara cepat, yang merupakan tantangan utama masalah kesehatandimasayangakan dating (Depkes RI, 2006 dalam Ekowati, 2009).

Tekanan darah merupakan faktor yang amat penting pada system sirkulasi. Peningkatan atau penurunan tekanan darah akan mempengaruhi homeostasis di dalam tubuh. Tekanan darah selalu diperlukan untuk daya dorong mengalirnya darah di dalam arteri, arteriola, kapiler dan system vena,sehingga terbentuklah suatu aliran darahyang menetap (IbnuM, 1996 dalam Febby, 2012).

Seseorang akan dikatakan hipertensi bila memiliki tekanan darah sistolik $\geq 140 \mathrm{mmHg}$ dan atau tekanan darah diastolik $\geq 90 \mathrm{mmHg}$, pada pemeriksaan yang berulang (disadur dari
A Statement by the American Society of Hypertension and the International Society of Hypertension 2013 dalam PERKI 2015). Hipertensi merupakan faktor resiko beberapa penyakit, terutama penyakit-penyakit yang berkaitan dengan sistem sirkulasi dan pembuluh darah (WHO, 2001).

Prevalensi Hipertensi seluruh dunia diperkirakan mencapai 28.6\%. Menurut hasil Riset Kesehatan Dasar (Riskesdas) tahun 2013, yang dilakukan di Indonesia menunjukkan bahwa prevalensi hipertensi di Indonesia berdasarkan hasil pengukuran pada umur $\geq 18$ tahun sebesar 25.8\%, sedangkan di Provinsi Banten sebesar 23\%. Prevalensi di Kota Tangerang menurut hasil Riskesdas tahun 2007 terdapat 7\%, sedang pada Riskesdas 2013 tidak ditemukan laporan.Berdasarkan studi pendahuluan di Klinik X, didapatkan prevalensi hipertensi $11.13 \%$.

Faktor-faktor yang mempengaruhi terjadinya hipertensi dibagi dalam dua kelompok besar yaitu faktor yang tidak dapat dikendalikan seperti jenis kelamin, umur, genetik, ras dan faktor yang dapat dikendalikan seperti pola makan, kebiasaan olahraga, konsumsi garam, kopi, alkohol dan stres. Untuk terjadinya hipertensi perlu peran faktor risiko tersebut secara bersama-sama (common underlying risk factor), dengan kata lain satu faktor risiko saja belum cukup menyebabkan timbulnya hipertensi (Depkes RI, 2003).

\section{METODE PENELITIAN}

Penelitian ini dilakukan di Klinik X di Kota Tangerang tahun 2016.Populasi dalam penelitian ini adalah pengunjung klinik berumur 18 tahun ke atas yang 
berobat jalan di Klinik $\mathrm{X}$ di Kota Tangerang pada tahun 2016.Dengan jumlah sampel 210.

Rancangan penelitian ini adalah crosssectional dengan pendekatan kuantitatif. Pengumpulan data dilakukan dengan data primer melalui wawancara dengan menggunakan kuesioner dan pengukuran tekanan darah, berat badan dan tinggi badan.

Analisis dengan menggunakan uji statistic chi-square. Dengan tingkat kepercayaan $95 \%$ pada tabel silang $2 \times 2$. Nilai OR dikatakan bermakna jika $p$ (value) lebih kecil dari $\alpha=0,05$ sehingga $\mathrm{H} 1$ diterima berarti hubungan antara variabel independen dengan variable dependen.

\section{HASIL DAN PEMBAHASAN}

Tabel 1

\section{Hasil Analisis Univariat}

\begin{tabular}{|c|c|c|c|c|}
\hline $\begin{array}{l}\mathrm{N} \\
\mathrm{o}\end{array}$ & Variabel & Kategori & $\begin{array}{c}\text { Jumla } \\
\mathrm{h}\end{array}$ & $\begin{array}{c}\text { Persen } \\
\text { tase } \\
(\%)\end{array}$ \\
\hline \multicolumn{5}{|c|}{ Dependen } \\
\hline \multirow[b]{2}{*}{1} & \multirow[b]{2}{*}{$\begin{array}{c}\text { Tekanan } \\
\text { Darah }\end{array}$} & Hipertensi & 42 & 20 \\
\hline & & $\begin{array}{l}\text { Tidak } \\
\text { Hipertensi }\end{array}$ & 168 & 80 \\
\hline & \multicolumn{4}{|l|}{$\begin{array}{l}\text { Independ } \\
\text { en }\end{array}$} \\
\hline \multirow[b]{2}{*}{1} & \multirow{2}{*}{ Umur } & $\begin{array}{l}\text { Tua }(\geq 45 \\
\text { tahun })\end{array}$ & 110 & $\begin{array}{l}52 \\
.4\end{array}$ \\
\hline & & $\begin{array}{l}\text { Muda }(<45 \\
\text { tahun) }\end{array}$ & 100 & $\begin{array}{l}47 \\
.6\end{array}$ \\
\hline \multirow[t]{2}{*}{2} & \multirow{2}{*}{$\begin{array}{c}\text { Jenis } \\
\text { Kelamin } \\
\text { beresiko }\end{array}$} & $\begin{array}{l}\text { Jenis kelamin } \\
\text { beresiko } \\
\text { (wanita } \geq 45 \\
\text { tahun dan } \\
\text { laki-laki }<45 \\
\text { tahun) }\end{array}$ & 117 & $\begin{array}{l}55 \\
.7\end{array}$ \\
\hline & & $\begin{array}{l}\text { Jenis kelamin } \\
\text { tidak beresiko } \\
\text { (laki-laki } \geq 45 \\
\text { tahun dan } \\
\text { wanita<45 }\end{array}$ & 93 & $\begin{array}{c}44 \\
.3\end{array}$ \\
\hline
\end{tabular}

\begin{tabular}{|c|c|c|c|c|}
\hline & & tahun) & & \\
\hline & \multirow[t]{2}{*}{$\begin{array}{c}\text { Kebiasaan } \\
\text { Olahraga }\end{array}$} & $\begin{array}{l}\text { Kurang/Cuku } \\
\mathrm{p}\end{array}$ & 133 & $\begin{array}{l}63 \\
.3\end{array}$ \\
\hline & & Baik & 7 & $\begin{array}{l}36 \\
.7\end{array}$ \\
\hline \multirow[t]{2}{*}{4} & \multirow{2}{*}{$\begin{array}{l}\text { Riwayat } \\
\text { Keturunan }\end{array}$} & $\begin{array}{l}\text { Ada } \\
\text { Keturunan } \\
\text { Hipertensi }\end{array}$ & 155 & $\begin{array}{l}73 \\
.8\end{array}$ \\
\hline & & $\begin{array}{l}\text { Tidak Ada } \\
\text { Keturunan } \\
\text { Hipertensi }\end{array}$ & 55 & $\begin{array}{l}26 \\
.2\end{array}$ \\
\hline \multirow[b]{2}{*}{5} & \multirow{2}{*}{$\begin{array}{l}\text { Status } \\
\text { Pendidika } \\
\mathrm{n}\end{array}$} & Rendah & 43 & $\begin{array}{l}20 \\
.5\end{array}$ \\
\hline & & Sedang/Tinggi & 167 & $\begin{array}{l}79 \\
.5\end{array}$ \\
\hline \multirow[b]{2}{*}{6} & \multirow{2}{*}{$\begin{array}{c}\text { Status } \\
\text { Pekerjaan }\end{array}$} & Tidak Bekerja & 60 & $\begin{array}{l}28 \\
.6 \\
\end{array}$ \\
\hline & & Bekerja & 150 & $\begin{array}{l}71 \\
.4\end{array}$ \\
\hline \multirow[t]{2}{*}{7} & \multirow{2}{*}{$\begin{array}{c}\text { Pendapata } \\
\mathrm{n}\end{array}$} & $\begin{array}{l}\text { Rendah/Mene } \\
\text { ngah }\end{array}$ & 44 & 21 \\
\hline & & Tinggi & 166 & 79 \\
\hline
\end{tabular}

Tabel 2

Hasil Analisis Bivariat

\begin{tabular}{|c|c|c|c|c|}
\hline $\mathrm{N}$ & Variabel & P Value & OR & $95 \% \mathrm{Cl}$ \\
\hline 1 & Umur & 0.001 & 9.630 & $\begin{array}{l}3.6 \\
25.7\end{array}$ \\
\hline 2 & $\begin{array}{l}\text { Jenis } \\
\text { Kelamin } \\
\text { Beresiko }\end{array}$ & 0.972 & 1.075 & $\begin{array}{l}0.54 \\
2.12\end{array}$ \\
\hline 3 & Olah Raga & 0.163 & 1.824 & $\begin{array}{l}0.858 \\
3.877\end{array}$ \\
\hline 4 & $\begin{array}{l}\text { Riwayat } \\
\text { keturunan }\end{array}$ & 0.031 & 3.136 & $\begin{array}{l}1.164 \\
8.445\end{array}$ \\
\hline 5 & $\begin{array}{l}\text { Status } \\
\text { Pendidika } \\
\mathrm{n}\end{array}$ & 0.036 & 2.397 & $\begin{array}{l}1.125 \\
5.105\end{array}$ \\
\hline 6 & $\begin{array}{l}\text { Status } \\
\text { Pekerjaan }\end{array}$ & 0.001 & 3.308 & $\begin{array}{l}1.638 \\
6.681\end{array}$ \\
\hline 7 & $\begin{array}{l}\text { Pendapata } \\
n\end{array}$ & 0.016 & 2.663 & $\begin{array}{l}1.261- \\
5.622\end{array}$ \\
\hline
\end{tabular}


Hasil dari analisis bivariate, terdapat 4 variabel yang berhubungan signifikans dengan hipertensi, yaitu variabel umur $(\mathrm{p}$ value $=0.001)$, riwayat keturunan $(\mathrm{p}$ value $=0.031)$, pendidikan ( $\mathrm{p}$ value $=0.036)$, pekerjaan $(\mathrm{p}$ value $=0.001) \mathrm{dan}$ pendapatan $(p$ value $=0.016)$

\section{Analisis Multivariat}

Pada seleksi bivariate terdapat delapan variabel yang memiliki $\mathrm{p}$ value $<0,25$ yaitu variabel adalah umur ( $p$ value $=0.001)$, riwayat keturunan $(\mathrm{p}$ value $=0.031)$, Pendidikan $(\mathrm{p}$ value $=$ 0.036), dan Pekerjaan $(\mathrm{p}$ value $=0.001)$.

\begin{tabular}{|l|l|c|c|c|}
\hline Variabel & $\mathrm{B}$ & $\begin{array}{c}\mathrm{P} \\
\text { Value }\end{array}$ & OR & $95 \mathrm{CI})$ \\
\hline Umur & 2.13 & 0.00 & 8.431 & $2.937-$ \\
& 2 & 0 & & 24.202 \\
\hline Riwayat & 1.32 & 0.03 & 3.744 & $1.130-$ \\
keturuna & 0 & 1 & & 12.410 \\
$\mathrm{n}$ & & & & \\
\hline Olahrag & 0.55 & 0.22 & 1.748 & $0.715-$ \\
$\mathrm{a}$ & 8 & 1 & & 4.271 \\
\hline Pendidi & 0.80 & 0.08 & 2.225 & $0.894-$ \\
kan & 0 & 6 & & 5.539 \\
\hline Pekerjaa & 0.63 & 0.12 & 1.883 & $0.841-$ \\
$\mathrm{n}$ & 3 & 4 & & 4.219 \\
\hline Pendapa & 1.55 & 0.00 & 4.741 & $1.835-$ \\
tan & 6 & 1 & & 12.246 \\
\hline Consnta & - & & 0.155 & \\
$\mathrm{t}$ & 1.86 & 0.004 & & \\
& 4 & & & \\
\hline
\end{tabular}

Keempat variabel tersebut dikeluarkan satu persatu dimulai dari variabel yang mempunyai $p$ value terbesar.Variabel obesitas , perkawinan, tetap dikeluarkan dari pemodelan karena pada saat dikeluarkan dari pemodelan, tidak ada variabel yang OR nya berubah $>10 \%$. Sedangkan variabel olahraga, pekerjaan dan pendidikan ada variabel yang OR nya berubah $>10 \%$, sehingga dimasukkan kembali ke pemodelan, dan dianggap sebagai confounding. Model terakhir dari analisis multivariat dengan uji regresi linier ganda setelah melewati seleksi bivariat dan seleksi multivariat adalah sebagai berikut:

Dari analisis Multivariat terlihat bahwa variabel yang berhubungan bermakna dengan kejadian Hipertensi Di Klinik X di Kota Tangerang pada tahun 2016 adalah variabel Umur, Riwayat keturunan, dan pendapatan.Sedangkan variabel yang menjadi confounding adalah 1) variabel olah raga merupakan confounding terhadap riwayat keturunan dan variabel pekerjaan, 2) variable Pekerjaan merupakan confounding dengan variabel Umur, Riwayat keturunan dan Olah Raga, 3) variabel pendidikan merupakan confounding terhadap riwayat keturunan dan Pekerjaan

\section{Pembahasan}

Umur

Semakin umur bertambah, terjadi perubahan pada arteri dalam tubuh menjadi lebih lebar dan kaku yang mengakibatkan kapasitas dan rekoil darah yang diakomodasikan melalui pembuluh darah menjadi berkurang. Pengurangan ini menyebabkan tekanan sistol menjadi bertambah.Menua juga menyebabkan ganggun mekanisme neurohormonal seperti system reninangiotensin-aldosteron dan juga menyebabkan meningkatnya konsentrasi plasma perifer danjuga adanya Glomerulosklerosis akibat penuaan dan intestinal fibrosis mengakibatkan peningkatan vasokonstriksi dan ketahanan vaskuler, sehingga akibatkan meningkatnya tekanan darah (hipertensi). Hasil penelitian menununjukkan, mereka dengan umur tua ( $\geq 45$ tahun) lebih beresiko 8.4 kali (C.I $95 \%$ : OR 2.9-24.2) menderita hipertensi bila dibandingkan dengan 
mereka yang berumur muda $(<45$ tahun).

\section{Riwayat keturunan,}

Secara teori banyak gen turut berperan pada perkembangan gangguan hipertensi. Seseorang yang mempunyai riwayat keluarga sebagai pembawa (carier) hipertensi mempunyai resiko dua kali lebih besar untuk terkena hipertensi.Gen simetrik memberi kode pada gen aldosteron sintase, sehingga menghasilkan produksi ektopik aldosteron, mutasi gen Saluran natrium endotel mengakibatkan peningkatan aktifitas aldosteron, penekanan aktifitas renin plasma dan hypokalemia, Kerusakan menyebabkan sindrom kelebihan mineralokortikoid. Dengan meningkatnya aldosteron menyebabkan meningkatnya retensi air, sehingga meingkatkan tekanann darah. Hasil penelitian menunjukkan mereka yang ada riwayat keturunan hipertensi lebih beresiko 3.7 kali (C.I $95 \%$ : OR 1.1312.4) menderita hipertensi bila dibandingkan dengan mereka yang tidak ada riwayat keturunan hipertensi.

\section{Pendapatan}

Faktor resiko hipertensi seperti overweight dan obesitas banyak dialami oleh kelompok yang berpendapatan tinggi . Di Indonesia terdapat pergeseran pola makan, yang mengarah pada makanan cepat saji dan yang diawetkan yang kita ketahui mengandung garam tinggi, lemak jenuh, dan rendah serat mulai menjamur terutama di kota-kota besar di Indonesia. Dan orang dengan pendapatan tinggi banyak yang terbiasa dengan makanan cepat saji ini. Hasil penelitian menunjukkkan mereka dengan pendapatan tinggi lebih beresiko 4.7 kali (C.I 95\%: OR 1.8-12.2) menderita hipertensi bila dibandingkan dengan mereka dengan pendapatan rendah dan sedang

\section{KESIMPULAN}

Proporsi penderita hipertensi di Klinik X di Kota Tangerang tahun 2016 adalah sebesar $20 \%$.

Variable yang mempunyai hubungan sebab akibat dengan kejadian Hipertensi di Klinik X di Kota Tangerang tahun 2016 berturut turut adalah sebagai berikut:

a. Umur tua ( $\geq 45$ tahun) mempengaruhi kejadian hipertensi 8,4 kali dibandingkan dengan mereka yang berumur muda ( $<45$ tahun).

b. Pendapatan tinggi mempengaruhi kejadian hipertensi 4,7 dibandingkan dengan mereka dengan pendapatan rendah dan sedang.

c. Riwayat keturunan hipertensi mempengaruhi kejadian hipertensi 3.7 kali dibandingkan dengan mereka yang tidak ada Riwayat keturunan.

Variabel yang menjadi confounding adalah variabel olah raga dan pendidikan merupakan confounding terhadap riwayat keturunan.

Variable independen yang tidak memiliki hubungan statistic signifikan dengan kejadian hipertensi adalah jenis kelamin beresiko.

Rekomendasi dapat diberikan terutama untuk variabel-variabel yang dapat dimodifikasi :

- Supaya tidak terjadi hipertensi perlu dilakukan kegiatan untuk memodifikasi prilaku untuk mencegah hipertensi terutama mereka yang mempunyai riwayat keturunan hipertensi dan berumur $\geq$ 45 tahun, dengan berhenti merokok, menjaga barat badan agar tidak obesitas, rutin berolah raga, mengurangi makanan mengandung tinggi garam, tinggi lemak. 
- Direkomendasikan mereka dengan riwayat keturunan hipertensi supaya tidak hipertensi sebaiknya rajin berolah raga, juga bagi meraka yang tidak bekerja dan berpendidikan rendah. Atas dasar rekomendasi ini disarankan disarankan

- Direkomendasikan seseorang dengan pendapatan tinggi memperhatikan pola hidupnya dan menghindari faktor resiko lain dari hipertensi. Atas dasar rekomendasi tersebut disarankan disarankan.

\section{DAFTAR PUSTAKA}

Lapau, Buchari. 2013. Metode Penelitian Kesehatan Metode Ilmiah Penulisan Skripsi, Tesis, dan Disertasi (edisi 2). Jakarta: Yayasan Pustaka Obor Indonesia.

\section{_ _ _ _ _ _. 2013. Prinsip Dan Metode Epidemilogi edisi 1. Jakarta: Badan Penerbit FKUI.}

Natalia, Diana. et el. 2015.Hubungan Obesitas dengan Kejadian Hipertensi di Kecamatan Sintang, Kalimantan Barat.Pontianak: Universitas Tanjungpura. hlmn. 336-338. CKD-228, Vol 42 No. 5.

Price, Sylvia Anderson, dan Wilson, Lorraine McCarty. 1995. Hipertensi dalam Patofisiologi:

Konsep Klinis Proses-Proses Penyakit. Jakarta: Penerbit Buku Kedokteran EGC.

Riskesdas. 2007. Laporan Hasil Riset Kesehatan Dasar (Riskesdas) Nasional Tahun 2007, Jakarta: Departemen Kesehatan RI.

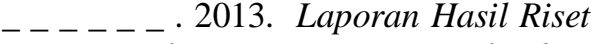

Kesehatan Dasar (Riskesdas) Nasional Tahun 2013, Jakarta: Departemen Kesehatan RI.
}

Roina, Eka Megawati. 2013. Buku Ajar Patofisiologi Mekanisme Terjadinya Penyakit. Tangerang Selatan: BINARUPA AKSARA Publisher.

Sani, Aulia. 2008. Hypertension Current Perspective. Jakarta: Meydya Crea.

Sulistiyowati. 2009. Faktor-Faktor Yang Berhubungan Dengan Kejadian Hipertensi di Kampung Button Kelurahan Magelang Tahun 2009 [Skripsi], Ilmu Kesehatan Masyarakat, Semarang: UniversitasNegeri Semarang.

Suoth, Meylen. 2014.HubunganGayaHidup Dengan Kejadian Hipertensi di Puskesmas Kolongan Kecamatan Kalawat Kabupaten Minahasa Utara.Ejournal keperawatan (e-Kp) Vol. 2. No. 1.

Suyono, Slamet. 2001. Buku Ajar Penyakit Dalam Jilid II. FKUI. Jakarta: BalaiPustaka.

W. Aru Sudoyo. 2009. Buku ajar ilmu penyakit dalam Jilid 2 edisi 5. Jakarta: Internalpublishing.

Wijaya, Caroline. 1995. Patofisiologi Konsep Klinis Proses-Proses Penyakit. Jakarta: Penerbitan Buku Kedokteran EGC.

Yanuar, Luqman Rachman. et el. 2008. Buku Ajar Fisiologi Kedokteran. Jakarta: Penerbitan Buku Kedokteran EGC. 